\title{
The Dynamic Location Model to Consider Background Traffic
}

\author{
Nahry Yusuf, Sutanto Soehodho \\ Department of Civil Engineering, Faculty of Engineering, Universitas Indonesia, Depok, Indonesia \\ Email: nahry@eng.ui.ac.id, ssoehodho@yahoo.com
}

Received October 15, 2011; revised November 17, 2011; accepted December 9, 2011

\begin{abstract}
This study concerns to the determination of location of freight distribution warehouses. It is part of a series of research projects on a distribution system we developed to deal with cases in a public service obligation state-owned company (PSO-SOC). This current research is characterized by the consideration of background traffic of the entire time period of planning rather than one certain time target on location model. It is aimed that the location decision to be more applicable and accommodative to the dynamic of the traffic condition. Once the decision is implemented, it will give the best outcome for the entire time period, not only for the initial time, end time or certain time of time period. A heuristic approach is proposed to simplify complexity of the model and network representation technique is applied to solve the model. A hyphotetical example is discussed to illustrate the mechanism of finding the optimal solution in term of both its objective function and applicability.
\end{abstract}

Keywords: Background Traffic; Location Model; Freight Distribution

\section{Introduction}

Research on determination location of facilities of freight distribution system has been done for many years. Those research works are differentiated in many aspects, such as number of types of commodities, number of channels, variables involved, mathematical complexity, objective of the system, and other features [1-4]. Nevertheless, this research area is still challenging to be explored in order to enhance the previous works and solve particular problems.

This current research is part of series of research on location model which concerns to Public Service Obligation State-Owned Company's (PSO-SOC) distribution system [5-7]. It is a continuation of our most recent research concerning the dynamic of background traffic [8]. Background traffic is the terminology used for the movement of vehicles which occupy the highway system together with freight vehicles. In our previous model, we considered the effect of background traffic on the location decision of warehouses. Such model, as well as other previous location models takes into account the background traffic of certain time target (time reference). Most of them do not mention explicitly which part of time period of planning to represent the traffic condition [9]. As the location decision is designed for a long time period, such as 15 - 20 years, and it is commonly known that the traffic is very dynamic in nature, then to consider only one certain time to be the reference of the number of background traffic may cause the decision obsolete prior to its final year.

In order to accommodate the dynamic of background traffic, we propose a dynamic location model which considers the fluctuation of background traffic using time increment during time period of planning. The location decision of such model is amenable for people to construct or operate warehouses in stages throughout time period of planning. This current research is focused to develop the mechanism of choosing the best combination of warehouses to be opened to accommodate the real traffic condition at the most and at the same time it could be applicable in practice.

The structure of this paper is as follows. Section 2 introduces the model formulation and Section 3 presents the model solution. An illustrative example is discussed in Section 4 to show the mechanism proposed in Section 3. Finally, Section 5 provides conclusion and future research directions.

\section{Model Formulation}

In order to show the effect of the dynamic of background traffic on the location decision, Figure 1 shows the relations among the determinants of location decision.

From Figure 1 it is shown that the existence of certain warehouse may generate traffic flow, both in direct and indirect way. It is clear that the activities of warehouse must produce and attract some traffic flows in direct way, 


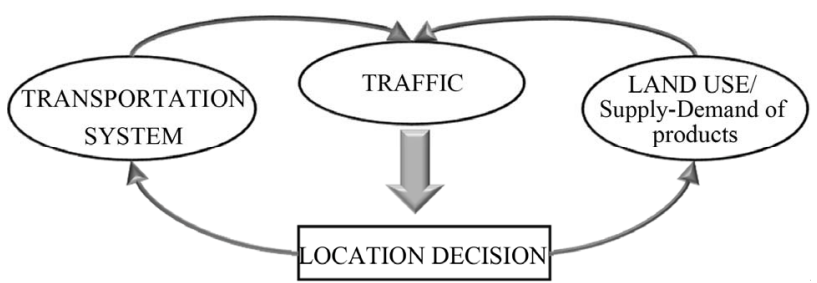

Figure 1. The relations among determinants of location decision.

while they also trigger the side activities in the vicinity of the warehouse which may generate traffic as well. Moreover, as the transportation supply and land use changed, the pattern of traffic flow may also be changed and it may leads to the obsolescence of the existence of warehouses. From such dynamic relation, it can be said that the existence of warehouses at certain time is affected by the traffic flow at that time, while traffic flow at certain time is affected by the location decision made at some time behind.
In order to formulate such dynamic relation, we make use of Network Representation approach. Network Representation (NR) is a technique to solve model by representing mathematical model as network flow-based formulation [10] and it is characterized by the use of diagram (network) to represent visually the components of the model. An example of NR of our model is shown in Figure 2.

Network Representation is developed by adding some dummy links and nodes into the original (physical) network, in which the function of those dummy links are designated to represent production cost, transportation cost, fixed cost of facility, as well as revenue. Such NR is designed to solve the following mathematical programming (Equatuion (1)):

subject to :

$$
\begin{aligned}
& \sum_{i} q_{i l m}\left(t_{n}\right)-\sum_{j} q_{l j m}\left(t_{n}\right)=\pi_{l m}\left(t_{n}\right), \\
& \forall l \in N, m \in M, t_{n} \in T
\end{aligned}
$$

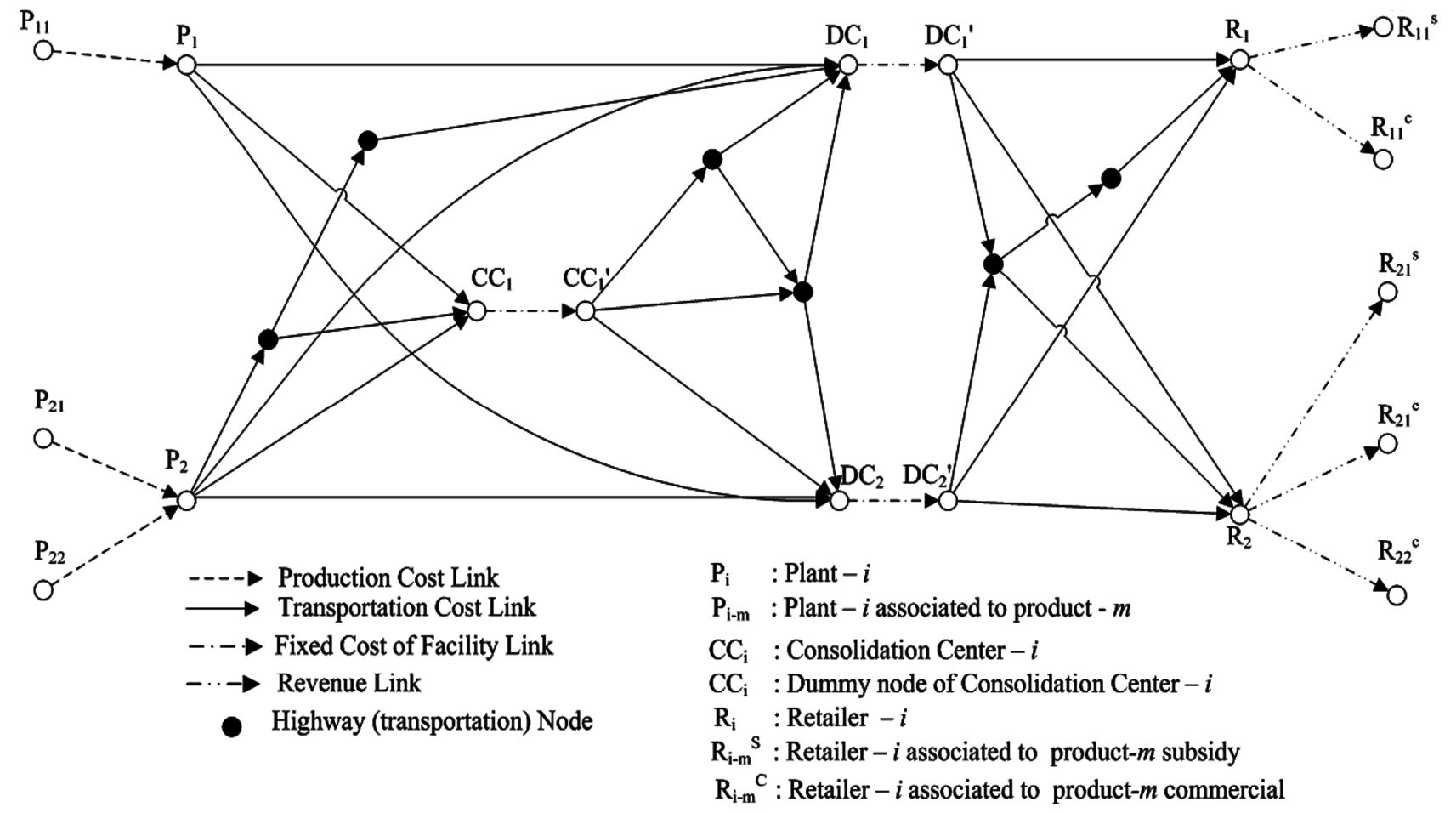

Figure 2. An example of network representation of proposed model. 


$$
q_{i j m}\left(t_{n}\right) \leq Y_{i j}\left(t_{n}\right) \cdot \sum_{s \in S_{m}} \pi_{s}\left(t_{n}\right),
$$

$\forall(i, j) \in$ Fixed Cost of Facility Link, $\forall m \in M, t_{n} \in T$

$$
\begin{gathered}
q_{i j m}\left(t_{n}\right) \geq 0, \forall(i, j) \in A, m \in M, t_{n} \in T \\
Y_{i j}\left(t_{n}\right)=[0,1], \forall(i, j) \in A, t_{n} \in T
\end{gathered}
$$

Sets:

$N$ : Set of nodes of network representation.

$A$ : Set of links of network representation.

$T$ : Set of time of observation.

$S_{m}$ : Set of plant nodes associated to product- $m$.

$M$ : Set of products.

Decision Variables:

$q_{i j m}\left(t_{n}\right):$ quantity of product- $m$ that flow from $i$ to $j$ at the $n$-th time.

$Y_{i j}\left(t_{n}\right)=1$, if warehouse associated to $(i, j)$ is opened at the $n$-th time, otherwise $Y_{i j}=0$.

Input Parameters:

$P C_{i j m}\left(t_{n}\right)$ is the unit cost of production in plant- $j$ at the $n$-th time, where $j$ is plant node.

$v_{\text {cap }}$ is capacity of freight vehicle.

$x_{i j}\left(t_{n}\right)$ is background traffic flow at the $n$-th time.

$F C_{i j}\left(t_{n}\right)$ is fixed cost of facility of warehouse- $i$ at the $n$-th time, where $i$ is $C C$ or $D C$ node.

$S P_{i j m}\left(t_{n}\right)$ is the selling price of the product- $m$ at retailer $-i$ at the $n$-th time, where $i$ is retailer node.

$\pi_{l m}\left(t_{n}\right)$ is flow requirement of node- $l$ associated to product- $m$ at the $n$-th time, where: if $l$ is sink node, $\pi_{l m}=$ demand of product- $m$ in retailer associated to node- $l$ at the $n$-th time, if $l$ is source node, $\pi_{l m}\left(t_{n}\right)=$ capacity of plant associated to node- $l$ to produce product- $m$ at the $n$-th time, otherwise, $\pi_{l m}\left(t_{n}\right)=0$.

Input Function:

$\Phi_{i j}[$.$] : is per unit transportation cost from i$ to $j$ (a convex function of total quantity of traffic flow).

Equation (1) denotes the objective function of our proposed model. It is actually intended to maximize the profit, in which profit is represented by revenue minus cost. Surely, this objective function can be replaced by a minimization of minus profit, which is represented by cost minus revenue. All the variables of the model are represented in dynamic form and it is epitomized by the use of notation $\left(t_{n}\right)$. In order to state the variables in their dynamic form, we divide the time of planning $T$ into $n$-increment time. The time difference between two consecutive times $(\Delta t)$ does not need to be similar. For the example, for 20 years of period of planning, we may divide 20 years into 4 time increments with similar time increment $\Delta t$ and we may find 5 sets of time of observation, those are $t_{0}, t_{1}, t_{2}, t_{3}$ and $t_{4}$ The time $t_{0}$ is representation of the initial time of planning, $t_{1}$ is for the fifth year of time of planning, $t_{2}$ is for the tenth year of time of planning and so on. Since the model includes all the sets of time of observation, it is shown that the model is intended to optimize the costs of the entire time of planning simultaneously.

The first term of Equation (1) represents the production costs and it is a function of per unit of production cost and total number of flow of the associated link. In our $\mathrm{NR}$, links associated to production cost ( production cost links) have the unit cost which is related to the type of product and the plant that produce such product.

The second term of Equation (1) denotes the transportation cost. Here, both flows of freight vehicles and the ones of background traffic contribute to the cost of transportation. It is assumed that the unit cost of transportation will increase as the volume of traffic increased and the cost to transport any type of product is similar. BPR's convex function may be applied to count such cost and it generally assumes that the transportation cost is proportional to the travel time.

The fixed charge problem is shown in the third term of Equation (1), where the variable of fixed cost of facility is not affected by the number of flows. The cost of facility will be charged only if the warehouse is opened. The decision to open certain warehouse is depend on the binary number $Y_{i j}$. Equation (5) shows that $Y_{i j}$ will be valued by either 0 or 1 and it will come to the decision to close or open warehouse related to link $(i, j)$, respectively.

The last term of Equation (1) shows the component of revenue of the model and negative signed is introduced to represent the opposite character between revenue and cost. Revenue link is characterized by the per unit selling price of the product associated to the link.

It is clear that each of production cost link has zero value for its per unit transportation cost and other components of cost, and transportation cost link has zero value for its production cost and other costs, so on.

Minimization problem of the model is limited by the flow requirements which are related to the capacity of plants to produce each type of products and the demand of each retailer on such products. This constraint is shown in Equation (2). Equation (3) is applied to guarantee that there will be no flow through certain warehouse if such warehouse is not opened. Furthermore, Equation (4) is set as non negative flow constraint. It is also assumed that the warehouse is unlimited in its capacity.

The proposed model is closely related to the minimum cost flow problem. It is one of the network flow problem which is aimed to determine a least cost shipment of a commodity through a network in order to satisfy demands at certain nodes from available supplies at other nodes [11]. 


\section{Model Solution}

In order to minimize the complexity of the proposed model discussed in the previous section, we make use of heuristic approach to solve the problem. Figure 3 shows the mechanism which is used to synthesize the dynamic concept of the proposed location model. Based on the capacity of plant, demand of retailers, as well as the condition of the traffic and all related costs at time $t_{0}$, we can determine the decision to open a set of warehouses. Such decision may be derived from any location model which is aimed to minimize the cost of the system [6].

Furthermore, as the traffic changed after time $t_{0}$ due to land use development, included the warehouse activities, and the demand and supply side of the products may also be changed, we can determine the best set of warehouses for time $t_{1}$. The similar phenomenon is treated to make location decision of time $t_{2}, t_{3}$ and $t_{4}$.

In certain situation where the traffic change is predicted to be very dynamic, the shorter time of $\Delta t$ would be required to find the best location decision which fit to the real traffic condition at the most.

The decisions made for time $t_{1}-t_{4}$ are actually the best decision to locate the warehouses during the time period of planning. This mechanism is essentially represented in the proposed mathematical programming of Equation (1), in which the total cost of the system during the time period of planning is the summation of total cost of the system of all time observations during time period of planning. It is clear that the minimum cost of each time of observation must make contribution to the minimum cost of the entire time period of planning.

From the mathematical point of view, such location decision is guaranteed to be the best decision to locate some warehouses among one set of potential warehouses. However, in some condition the decision could not be applied in practice. It can be explained through Figure 3. From the example on Figure 3, it can be seen that warehouse 1, 2, 4 and 5 are opened at $t_{0}$ but warehouse 2 is not feasible to be opened at time $t_{1}$ and $t_{2}$ and it is replaced by warehouse 3 at time $t_{2}$. Practically it is actually not common to open and close warehouse consecutively and then open them at the following time, as experienced by warehouse 2 and 3 of the example (Figure 3). If this is the rule, justification should be made to decide the combination of warehouses which shall be the second best suited to the background traffic condition during the time period of planning while at the same it could be feasible from the practical side.

The mechanism of making location decision which taking into account the dynamic of traffic is presented in Figure 4 and it could be explained as follows:

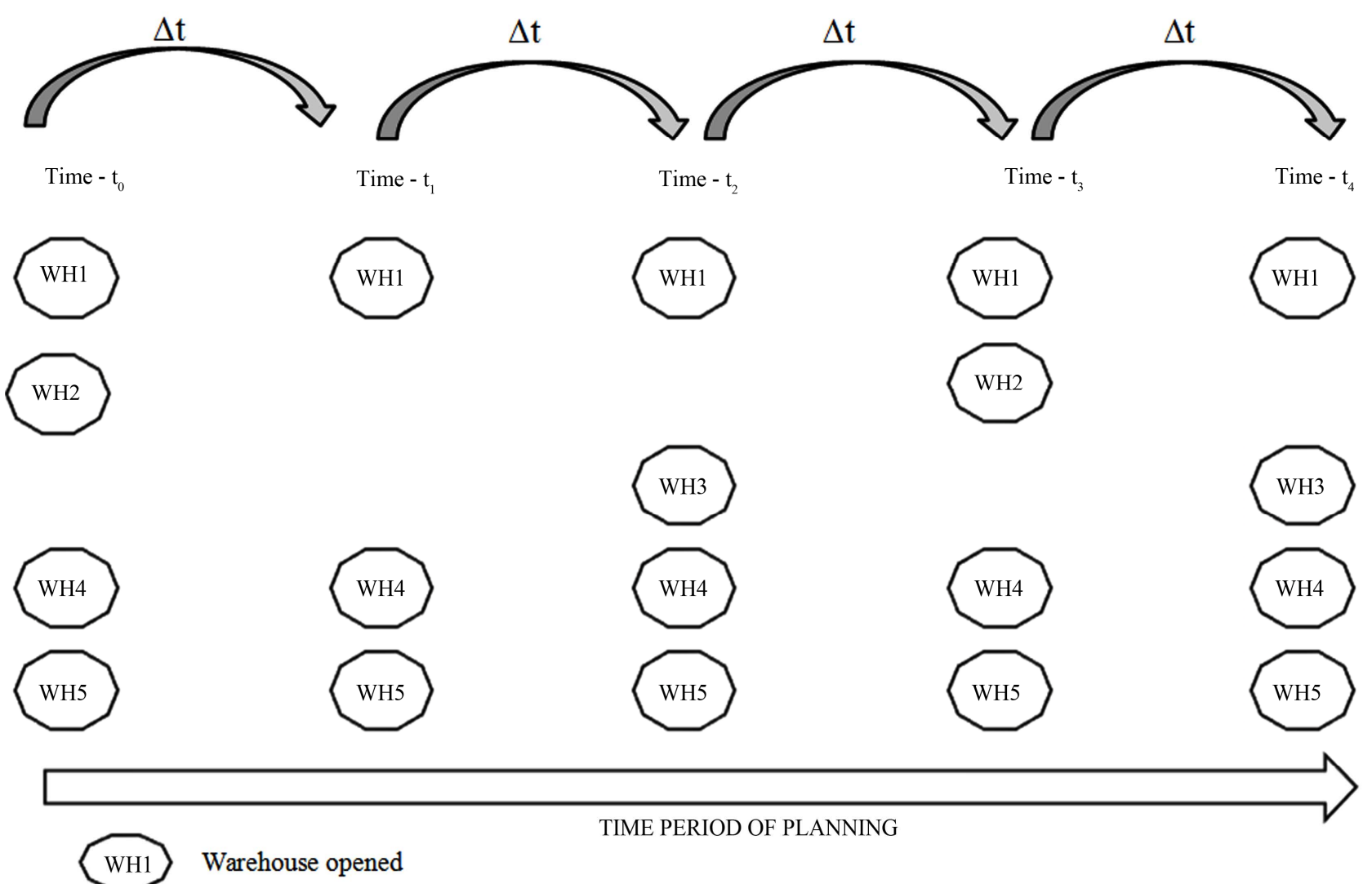

Figure 3. Dynamic of location decision. 


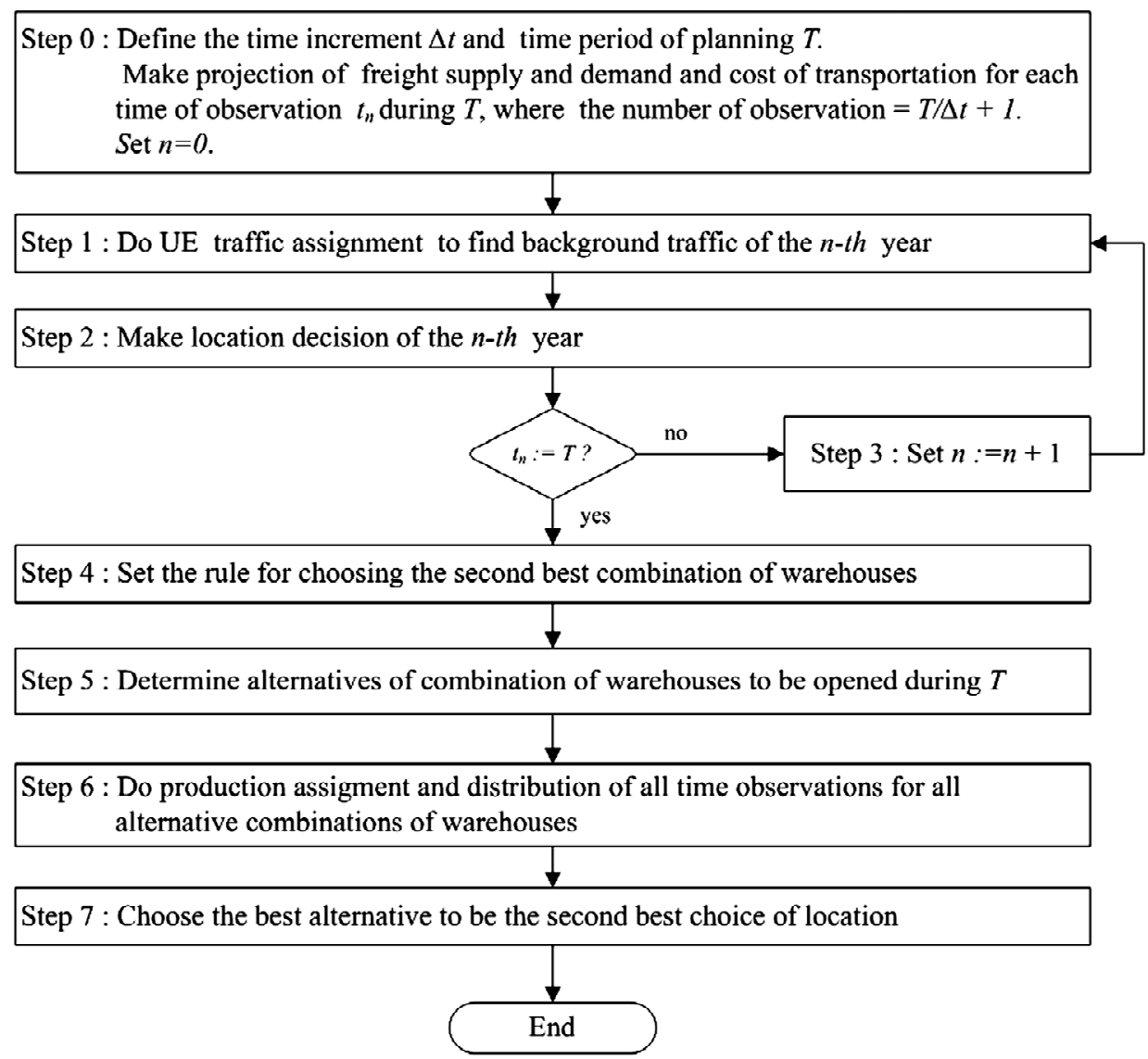

Figure 4. Step wise of choosing the second best combination of warehouses.

Step 0 : Define the time increment $\Delta t$ and time period of planning $T$.

Make projection of freight supply and demand and cost of transportation for each time of observation $t_{n}$ during $T$, where the number of observation $=T / \Delta t+1$. Set $n=0$.

Step 1: Do User Equilibrium traffic assignment to find background traffic of the $n$-th year. The assignment must be based on the forecasted generated trips due to land use development (included warehouse activities) during the period of $(n-1)$-th year to $n$-th year.

Step 2: Make location decision of the $n$-th year. If the $n$-th year is the final year $T$, go to Step 4 .

Step 3: Set $n:=n+1$, go to Step 1 .

Step 4: Set the rule for choosing the second best combination of warehouses.

Step 5: Determine alternatives of combination of warehouses to be opened during $T$.

Step 6: Do production assigment and distribution of all time observations for all alternative combinations of warehouses.

Step 7: Choose the best alternative to be the second best choice of location.

Some considerations could be used for the rule of determining alternatives of warehouse combination (Step 4).
The rule is applied to the initial (best) combination of warehouses and it could be explained as follows:

1) The most frequently appeared warehouses must become member of the second best combination.

2) When certain warehouse is opened at certain time, it must be opened until the final year $T$.

3) When there is more than $\Delta t$ years time lapse between two consecutive times of opening certain warehouse (see the example of warehouse 2 or 3 in Figure 3), coefficient $\alpha$ could be used for final decision.

4) Coefficient $\alpha$ represents the tolerable percentage of lapse time between two consecutive times of opening certain warehouse if it is compared to time $T$.

5 ) The most frequently appeared combination of warehouses (at the initial condition) could be the alternative combination.

By applying such rules, we can find one or more alternatives of combination and we can compare the objective function of all the alternatives and finally choose the best one.

\section{Illustrative Example}

In order to show the mechanism proposed in Section 3, the ensuing contrived example is discussed. The 2-stage 
distribution network consists of 2 plants, 2 potential sites of distribution center level 1, 3 potential sites of distribution centers level 2 and 3 retailers (Figure 5). It deals with 1 type of product and 2 types of demand, those are commercial and subsidized demand. Table 1 shows capacity of each plant, as well as its production cost. Table 2 shows the demand of each retailer on each product, as well as its selling price.

We design the time period of planning $T$ as 20 years, with the increment time is 5 years, so that we have 5 times of observation. As the scenario of the system, the capacity of some links of the network is set to be 1.5 times of its initial capacity at year 10 (time $\left.t_{2}\right)$ and some other links's are increased at year 15 (time $t_{3}$ ). Regarding the tolerable percentage of lapse time between two consecutive times of opening certain warehouse, we assume to apply coefficient $\alpha$ as $20 \%$. It implies that we may consider the existence of certain warehouse only if maximum time lapse between two consecutive times of opening such warehouse is 10 years (equal to 1 time of observation).

The solution is initialized by carrying out the traffic assignment for the initial time $t_{0}$. Using any kind of traffic assignment tool, link traffic flow for the entire network could be determined. Based on these flows and other parameters of supply and demands of products, location decision of time $t_{0}$ could be determined using any kind of location model [6]. Figure 6 shows that warehouse 2, 3, 4 and 5 is the best combination for time $t_{0}$. Furthermore, having the best location of time $t_{0}$, we can make projection of the generated trips for time $t_{1}$ due to the land use development during time $t_{0}$ to $t_{1}$, included the activities of warehouses, and it is then followed by the prediction of background traffic of the entire network for time $t_{1}$. Again, based on these flows and the projection of demand and supply of the products at time $t_{1}$, location decision of time $t_{1}$ is determined. Furthermore, the location decisions of the remaining time of observation may be determined with the similar way. The more the number of time increment (time of observation), the more fit the decision to the real condition of traffic. From this notion, we may also find that if the location model only considers one certain time for representing the background traffic (such as initial time, mid year or final year), we may lose the opportunity to reduce the cost (or increase the profit) from the system.

Figure 6 shows the best combination of warehouses of the illustrative example for the entire period of planning. From Figure 6, it can be seen that at the initial time $\left(t_{0}\right)$ the best composition of warehouses is $2,3,4$, and 5 . At time $t_{1}$, the location decision is not changed even though the composition of background traffic is changed. As some link capacities are changed at time $t_{2}$, the composition of warehouses is changed to warehouse 1 and 4 . Finally, at time $t_{3}$ and $t_{4}$ warehouse $1,3,4$ and 5 become the best composition. Since such compositions are derived from the location model which is applied at the entire time period of planning, it is clear that the combination of warehouses on Figure 6 could be considered as the best composition of warehouses.

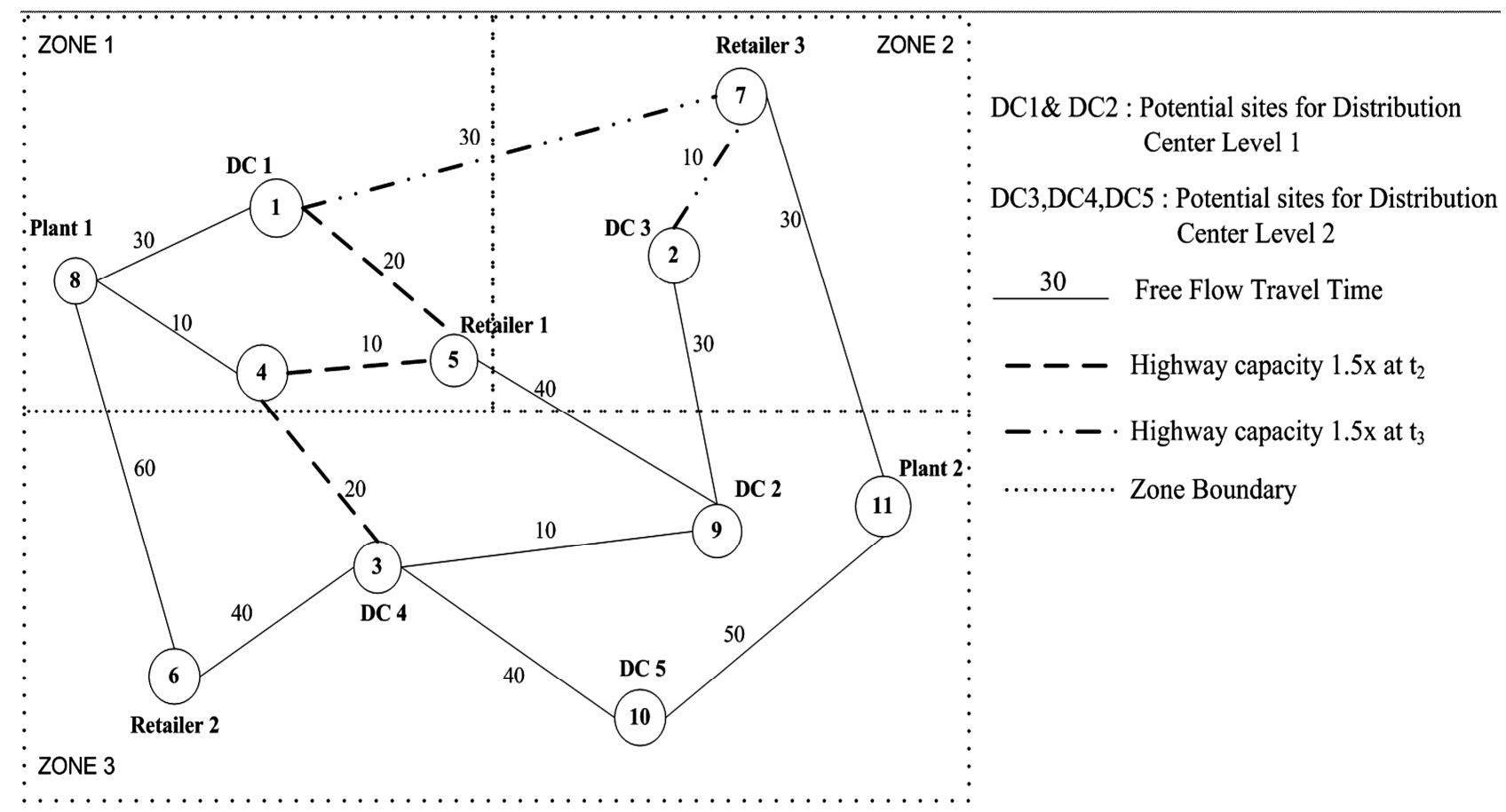

Figure 5. Distribution network of the example. 
Table 1. Plant capacity.

\begin{tabular}{cc}
\hline \multirow{2}{*}{ Plant } & Plant Capacity (unit cost of production) \\
\cline { 2 - 2 } & Product-1 \\
\hline 1 & $1000(4)$ \\
2 & $2000(5)$ \\
Total & 3000 \\
\hline
\end{tabular}

Table 2. Demand.

\begin{tabular}{ccc}
\hline \multirow{2}{*}{ Retailer } & \multicolumn{2}{c}{ Demand on product(selling price) } \\
\cline { 2 - 3 } & $1^{\mathrm{S}}$ & $1^{\mathrm{C}}$ \\
\hline 1 & $400(20)$ & $600(50)$ \\
2 & $200(20)$ & $700(75)$ \\
3 & $200(20)$ & $900(50)$ \\
Total & & 3000 \\
\hline
\end{tabular}

S: Subsidy, C: Commercial.

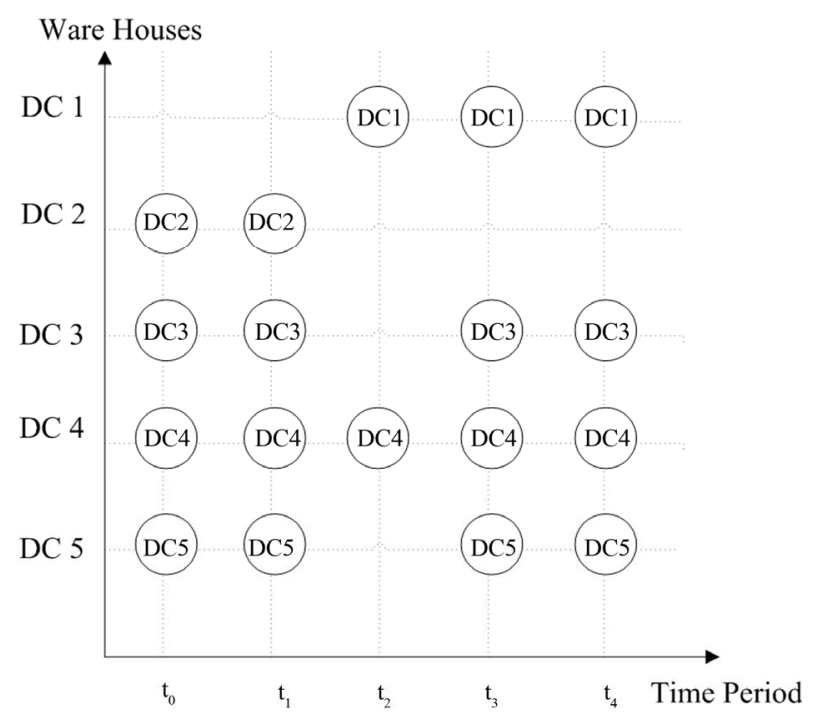

Figure 6. The (initial) best combination of warehouses (Objective function $=\mathbf{2 4 6 6 5 9}$ ).
Furthermore, when we investigate the best combination on Figure 6, we can see that warehouse 2 is actually not feasible to be opened since it is just opened at time $t_{0}$ and $t_{1}$, and it is not required at the remaining time. For warehouse 3 and 4 , even though they are not required at time $t_{2}$, we may still consider them due to the existence of the coefficient of $\alpha$.

By applying some rules as described in Section 3, we can propose 3 alternatives of combination of warehouses to be applied. For each of alternatives we can determine its objective function throughout the time period (Table 3). It is carried out in the slightly similar way with Step 1 and 2 of step wise on Figure 4. The only difference is the location decision of step 2 is replaced by allocation decision. In allocation problem, the existence (location) of warehouses is predetermined.

Figures 7(a)-(c) and Table 3 show the three alternatives, together with the associated objective function for the entire time of planning. Since our mathematical model is a minimization problem, in which the value of the objective function represents minus profit which will be gained by the company by opening the associated warehouses, the bigger the number, the worse the value of the decision. Since the initial best combination is found through the optimization of location model, then the objective functions of all the alternatives must be worse than the initial best one but it may be more practical to be applied.

From Figures 7(a)-(c) and Table 3, it can be seen that alternative 1 (Figure $\mathbf{7 ( a )}$ ) is the best among the three alternatives in term of its objective function and it indicates that warehouse $1,3,4$ and 5 are feasible to be opened during the time period of planning to replace the initial best combination as shown in Figure 6. From the context of objective function, it is understood that the alternative 1 is supposed to give more profit than the others and it is the closest alternative to the best one.

Table 3. The objective functions of the alternatives of warehouse combination.

\begin{tabular}{|c|c|c|c|c|c|c|}
\hline \multirow{2}{*}{$\begin{array}{l}\text { Alternatives of warehouse } \\
\text { combination }\end{array}$} & \multicolumn{6}{|c|}{ Objective Function (DC opened) } \\
\hline & $t_{0}$ & $t_{1}$ & $t_{2}$ & $t_{3}$ & $t_{4}$ & Total \\
\hline The initial (best) combination & $\begin{array}{c}-52,769 \\
(2,3,4,5)\end{array}$ & $\begin{array}{c}9198 \\
(2,3,4,5)\end{array}$ & $\begin{array}{c}50,244 \\
(1,4)\end{array}$ & $\begin{array}{c}76,872 \\
(1,3,4,5)\end{array}$ & $\begin{array}{c}163,014 \\
(1,3,4,5)\end{array}$ & 246,659 \\
\hline Alternative 1 & $\begin{array}{c}-35,507 \\
(1,3,4,5)\end{array}$ & $\begin{array}{c}29,769 \\
(1,3,4,5)\end{array}$ & $\begin{array}{c}122,439 \\
(1,3,4,5)\end{array}$ & $\begin{array}{c}76,872 \\
(1,3,4,5)\end{array}$ & $\begin{array}{c}163,014 \\
(1,3,4,5)\end{array}$ & 356,587 \\
\hline Alternative 2 & $\begin{array}{c}-52,769 \\
(2,3,4,5)\end{array}$ & $\begin{array}{c}9198 \\
(2,3,4,5)\end{array}$ & $\begin{array}{c}83,135 \\
(2,3,4,5)\end{array}$ & $\begin{array}{c}126,153 \\
(2,3,4,5)\end{array}$ & $\begin{array}{c}219,116 \\
(2,3,4,5)\end{array}$ & 384,833 \\
\hline Alternative 3 & $\begin{array}{c}-52,769 \\
(2,3,4,5)\end{array}$ & $\begin{array}{c}9,198 \\
(2,3,4,5)\end{array}$ & $\begin{array}{c}84,865 \\
(1,2,3,4,5)\end{array}$ & $\begin{array}{c}126,689 \\
(1,2,3,4,5)\end{array}$ & $\begin{array}{c}217,528 \\
(1,2,3,4,5)\end{array}$ & 385,511 \\
\hline
\end{tabular}




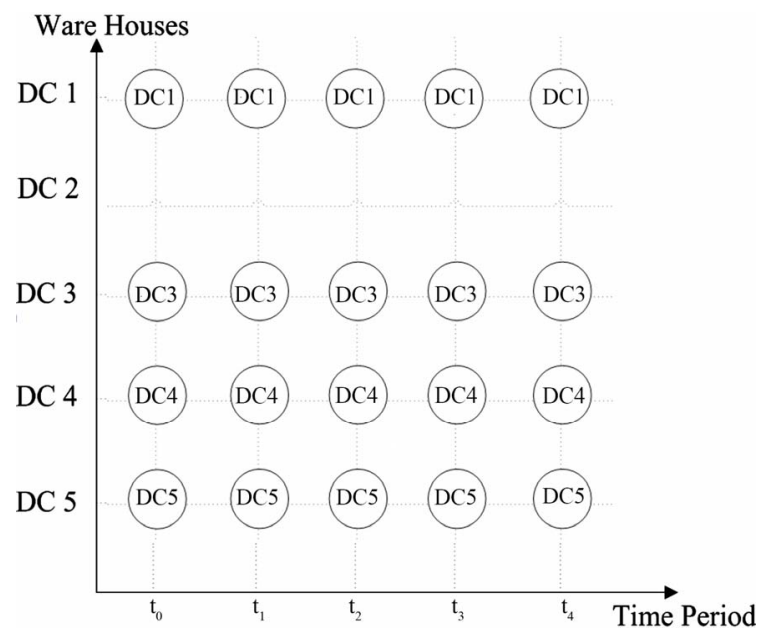

(a)

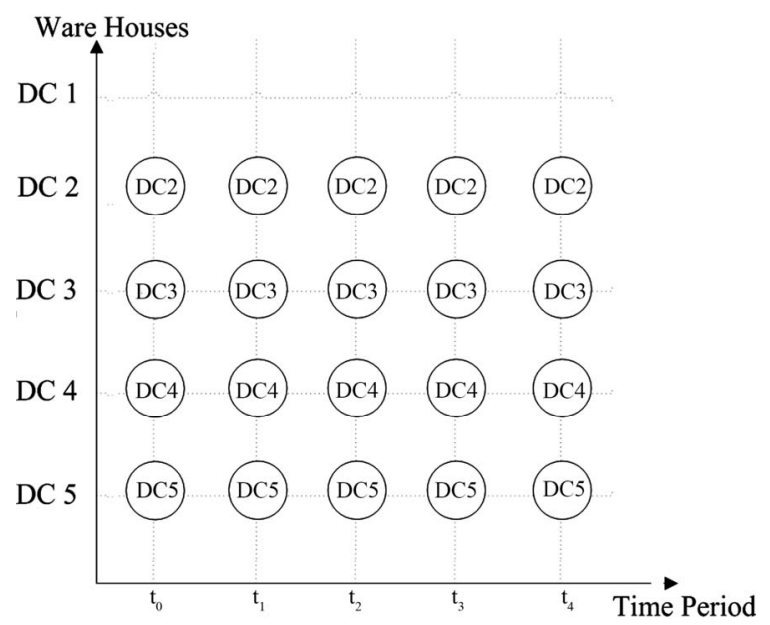

(b)

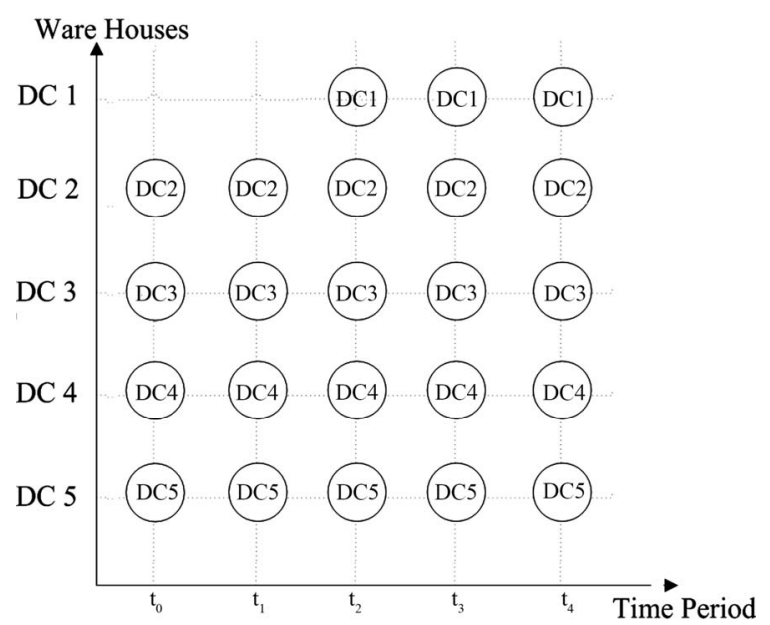

(c)

Figure 7. (a) The Alternative 1 of warehouse combination (Objective function = 356587); (b) The Alternative 2 of warehouse combination (Objective function = 384833); (c) The Alternative 3 of warehouse combination (Objective function $=385511$ ).

\section{Conclusions}

We propose a new approach of finding the best location of distribution warehouses which is aimed not only to minimize the cost (or maximize the profit) but also to accomodate the practical side of development a set of warehouses. The main characteristic of the model is the inclusion of the background traffic of the entire time period of planning which is divided into some increment times. The location decision could be utilized to build or open the warehouse(s) in stages during time period of planning.

Mechanism proposed to select the best composition of warehouses is dominated by the heuristic approach. Further research is recommended to scrutinize the rules of warehouse selection in order to find the second best decision which is as close as possible to the best one.

\section{REFERENCES}

[1] R. K. Ahuja, T. L. Magnanti and J. B. Orlin, "Network Flows," Prentice Hall, Hoboken, 1993.

[2] K. S. Bhutta, F. Huq, G. Frazier and Z. Mohamed, "An Integrated Location, Production, Distribution and Investment Model for a Multinational Corporation," International Journal Production Economics, Vol. 86, No. 3, 2003, pp. 201-216. doi:10.1016/S0925-5273(03)00046-X

[3] L. Dupont, "Branch and Bound Algorithm for a Facility Location Problem with Concave Site Dependent Costs," International Journal Production Economics, Vol. 112, No. 1, 2008, pp 245-254. doi:10.1016/j.ijpe.2007.04.001

[4] F. Glover, D. Klingman and N. V. Phillips, "Network Models in Optimization and Their Applications in Practice," John Wiley \& Sons, Inc., Hoboken, 1992. doi:10.1002/9781118033173

[5] Nahry and S. Soehodho, "Consideration of the Dy- namic of Traffic Congestion on Location Model," Proceedings the 16th HKSTS International Conference, Hong Kong, 2011, (Unpublished).

[6] G. T. Ross and R. M. Soland, "A Multicriteria Approach to the Location of Public Facilities," European Journal of Operational Research, Vol. 4, No. 5, 1980, pp. 307-321. doi:10.1016/0377-2217(80)90142-3

[7] S. Soehodho and Nahry, "Strategic Design of Dis- tribution System of State-Owned Companies: Preliminary Stage of Logistics Research Series and Evaluation on Model Parameters," International Journal on Logistics and Transportation, Vol. 3, No. 1, 2009.

[8] S. Soehodho and Nahry, "Traffic Flow Consideration in Design of Freight Distribution System," IATSS Research, Vol. 34, No. 1, 2010, pp. 55-61.

[9] S. Soehodho and Nahry, "Optimization of Location Model of Capacitated Network," Jurnal Transportasi, Vol. 11, No. 1, 2011, pp. 59-68.

[10] M. Sun, "Solving the Uncapacitated Facility Location Problem Using Tabu Search," Computers and Operations Research, Vol. 33, No. 9, 2006, pp. 2563-2589. 
doi:10.1016/j.cor.2005.07.014

[11] Y. Bai, T. Hwang, S. Kang and Y. Ouyang, "Biofuel Refinery Location and Supply Chain Planning under Traffic
Congestion," Transportation Research, Part B, Vol. 45, No. 1, 2011, pp. 162-175. doi:10.1016/j.trb.2010.04.006 